\title{
Prevalence of DLL3, CTLA-4 and MSTN Expression in Patients with Small Cell Lung Cancer
}

This article was published in the following Dove Press journal: OncoTargets and Therapy

\author{
Orgilmaa Regzedmaa ${ }^{1}{ }^{1, *}$ \\ Ying $\mathrm{Li}^{2, *}$ \\ Yongwen $\mathrm{Li} \mathbb{D}^{2, *}$ \\ Hongbing Zhang' \\ Jin Wang ${ }^{2}$ \\ Hao Gong' \\ Yin Yuan' \\ Weiting $\mathrm{Li}^{\prime}$ \\ Hongyu Liu ${ }^{2}$ \\ Jun Chen $\mathbb{D}^{1,2}$
}

'Department of Lung Cancer Surgery, Tianjin Key Laboratory of Lung Cancer Metastasis and Tumor Microenvironment, Tianjin Medical University General Hospital, Tianjin 300052, People's Republic of China; ${ }^{2}$ Tianjin Key Laboratory of Lung Cancer Metastasis and Tumor Microenvironment, Tianjin Lung Cancer Institute, Tianjin Medical University General Hospital, Tianjin 300052, People's Republic of China

*These authors contributed equally to this work
Correspondence: Jun Chen; Hongyu Liu Tianjin Key Laboratory of Lung Cancer Metastasis and Tumor Microenvironment, Tianjin Lung Cancer Institute, Tianjin Medical University General Hospital, Heping District, Tianjin 300052, People's Republic of China

Email huntercj2004@yahoo.com;

liuhongyu123@hotmail.com
Introduction: Immune-based and antibody-drug conjugate therapies have shown promise in the treatment of patients with small cell lung cancer (SCLC). However, better predictive biomarkers are needed for selection of the appropriate SCLC patients for these advanced therapies and also for evaluation of the efficacy of these treatments.

Objective: The aim of this study was to examine the expression of delta-like protein 3 (DLL3), cytotoxic T lymphocyte-associated protein 4 (CTLA-4), and mesothelin (MSTN) in patients with SCLC and compare them with those patients' clinical characteristics.

Methods: Immunohistochemical analyses of DLL3, CTLA-4 and MSTN expression were performed in 38 samples from patients with SCLC.

Results: We found that positive expression in patients of the biomarkers was as follows: for DLL3, 100\% (38/38), for CTLA-4, 89.5\% (36/38) and for MSTN 81.5\% (31/38). The median survival time was 17.9 months in the DLL3 high expression group and 23 months in the DLL3 low expression group. Patients with a high expression of DLL3 showed a poorer prognosis than those with a low expression of DLL3 (HR=3.4; 95\% CI, 1.34-8.6; $\mathrm{p}=0.01$ ). Conclusion: The expression of DLL3, CTLA-4 and MSTN was not correlated with patients' age, sex, smoking status, stage, and tumor metastasis. The fact that there was a higher expression of DLL3, CTLA-4, and MSTN in SCLC suggested that these molecules could be used as predictive biomarkers for SCLC.

Keywords: small cell lung cancer, DLL3, CTLA-4, MSTN, prognosis

\section{Introduction}

Lung cancer has now been confirmed as the most frequently occurring cancer worldwide, being responsible for 2.1 million new cases and 1.8 million deaths in 2018. ${ }^{1}$ Lung cancer is generally classified into two distinct types; small cell lung cancer (SCLC) and non-small cell lung cancer (NSCLC). SCLC prevalence is $12-15 \%$ of all lung cancers, accounting for over 275,000 of new lung cancerrelated cases worldwide annually. ${ }^{2,3}$ Currently the prognosis is poor, with a 5 -year survival rate at less than $7 \% .{ }^{4}$ Over the last few years however, there has been considerable progress in the treatment of SCLC. In 2018, the US Food and Drug Administration (FDA) approved the use of the immunotherapy checkpoint inhibitor nivolumab (Opdiva) for patients with SCLC who failed to respond to platinumbased chemotherapy with at least one other line of treatment. ${ }^{5}$ The drug Opdiva is a fully human IgG4 monoclonal antibody that primarily suppresses the programmed cell death 1 (PD-1) receptor, thereby effectively blocking the interaction of the PD1 receptor and its two distinct programmed death ligands PD-L1 and PD-L2. As a result, it can inactivate the negative regulatory mechanisms acting on T-cell 
activation and proliferation. ${ }^{6}$ Assisted by results of the recent IMpower study, accelerated approval was granted by the FDA in March 2019 for the combination of atezolizumab (Tecentriq) with carboplatin and etoposide in the frontline treatment of extensive-stage small cell lung cancer (ES-SCLC). ${ }^{7}$ The study demonstrated an overall survival benefit when the PD-L1 inhibitor atezolizumab was added to platinum/etoposide chemotherapy for the initial treatment of ES-SCLC, with median overall survival (mOS) being 12.3 months in the atezolizumab group and 10.3 months in the placebo group ( $\mathrm{HR}=0.70 ; 95 \% \mathrm{CI}$, 0.54-0.91; $\mathrm{p}=0.007){ }^{8}$ Thus, the immunotherapy/chemotherapy combination has now been recognized as an alternative choice for patients with SCLC and has played an increasing role in the treatment of this cancer.

DLL3, a cell surface protein, is abundantly expressed in high-grade neuroendocrine carcinomas of the lung including SCLC, and so can be used to target this cancer with tumor-selective treatment. It has been shown that the cellular NOTCH receptor is mainly downregulated by DLL3, thereby inhibiting the NOTCH signaling pathway within the cell. Therefore, DLL3 can also be used in cancer chemotherapy to target and suppress tumor cells. Rovalpituzumab Tesirine (Rova-T), a DLL3-targeted therapeutic agent containing humanized monoclonal antibody, was the first in the class of antibody-drug conjugates (ADCs). The mechanism of action of Rova-T can be explained as follows. Firstly, ADC becomes integrated with DLL3 on the surface of the tumor cell, forming an ADC-DLL3 complex. Then the ADC-DLL3 complex is internalized into the cell, triggering the release of SC DR002 via proteolytic cleavage in late endosomes. Crosslinks between the DNA strands caused by SC DR002 then produce a cytotoxic effect on tumor cells. In a phase I clinical trial, it was confirmed that Rova-T was more effective for SCLC with DLL3 over-expression compared with SCLC with a low level of DLL3 expressed. ${ }^{9,10}$ Hence, DLL3 might be a promising predictive marker suitable for treatment of SCLC. Currently the expression level of DLL3 in SCLC is still unclear however, and more work is required to ascertain the precise DLL3-related mechanisms taking place in SCLC.

CTLA-4, the homologue of the $\mathrm{T}$ cell co-stimulatory molecule CD 28, plays an important role in the downregulation of $\mathrm{T}$ cells, which deactivates or blocks the function of $\mathrm{T}$ cells. ${ }^{11}$ It has been established that the CTLA-4 checkpoint pathway is a crucial regulator for the early activation of T-cells in peripheral lymph tissues. ${ }^{12}$ Ipilimumab is a monoclonal antibody which suppresses the interaction between CTLA-4 and its binders, including CD80/CD86. As a consequence of suppressing the interaction of the down-regulator of the $\mathrm{T}$ cell, the activation and proliferation of the $\mathrm{T}$ cell are continually triggered and then easily diffuse into tumor tissue. A randomized, double-blinded and multi-center phase II trial showed the combination of ipilimumab with paclitaxel and carboplatin in 130 late-stage SCLC patients was free of any patient side effects. ${ }^{13}$ In addition, a metaanalysis of the prognostic value of CTLA-4 in various cancers showed a significant correlation between high expression of CTLA-4 and prolonged overall survival (OS) ${ }^{14}$ Clearly, CTLA-4 levels in SCLC should be the subject of further investigation.

MSTN is a glycosyl-phosphatidylinositol-anchored glycoprotein typically expressed on the surface of human solid tumor cells. MSTN was firstly discovered using monoclonal antibody $\mathrm{K} 1^{15}$ and is now in development as a therapeutic target agent for clinical use. ${ }^{16}$ It has been demonstrated that increased production of MSTN is detected in $30-70 \%$ cases of lung adenocarcinoma. ${ }^{17-20}$ Thomas et al in ClinicalTrials.gov (NCT01306045), have reported that a high expression of MSTN has a significant correlation with poor survival (median OS 18.2 months vs 32.9 months; $\mathrm{p}<0.014$ ). The study provides a strong rationale to intensively investigate anti-MSTN target therapies in advanced lung adenocarcinoma, especially in the KRAS-mutant subgroup.

However, the prevalence of DLL3, CTLA-4 and MSTN expression in SCLC patients, and their associations with patient clinicopathological characteristics, remains unclear. Therefore, in this study, we evaluated the expression of DLL3, CTLA-4, and MSTN in patients with SCLC and correlated these with the clinical characteristics of SCLC.

\section{Materials and Methods Research Cohort}

In this study, we enrolled 38 patients with SCLC who underwent surgical resection of primary lung cancer at the Department of Lung Cancer Surgery, Tianjin Medical University General Hospital during 2009-2014. The inclusion criteria were: (1) primary SCLC; and (2) patients had neither chemotherapy nor radiotherapy administered prior to surgery. Patients' demographics and clinical information were obtained from the hospital database. The clinical and 
pathological characteristics of the patients are detailed in Table 1. Lung cancer staging for each patient was performed according to the American Joint Committee on Cancer (AJCC) Staging Manual, Eighth Edition. ${ }^{21}$

\section{Immunohistochemistry}

Immunohistochemistry for DLL3, CTLA-4, and MSTN was performed as described previously. Paraffin-embedded lung tissue samples were cut into $4 \mu \mathrm{m}$ thick sections. The sections were deparaffinized in xylene and rehydrated in a graded ethanol series. Heat-induced antigen retrieval was carried out by microwave pretreatment in $5 \mathrm{mM}$ Tris- $\mathrm{HCl}$ (pH10.0) for $15 \mathrm{~min}$. After rinsing in PBS, the sections were incubated with rabbit polyclonal anti-DLL3 (1:400, No SAB1302862, Sigma-Aldrich, Shanghai, China), mouse monoclonal antibody anti-CTLA-4 (1:50, (F-8), sc376016, Alexa Fluor, Inc, Oregon USA) and rabbit monoclonal antibody anti-MSTN (1:100, [EPR4509] ab133489, Abcam, Shanghai, China) at $4^{\circ} \mathrm{C}$ overnight. After washing with phosphate buffered saline (PBS), slides were treated with a ready-to-use peroxidase-labeled polymer conjugated to goat anti-rabbit IgG (catalog no. SM801: EnVision+ kit; Dako; Agilent Technologies, Inc) as the secondary antibody for $30 \mathrm{~min}$ at room temperature. The staining was visualized with diaminobenzidine, and followed by counterstaining with hematoxylin. Slides for DLL3, CTLA-4, and MSTN

Table I Patient Characteristics

\begin{tabular}{|l|l|}
\hline Characteristic & N (\%) \\
\hline Gender & \\
Male & $26(68.4)$ \\
Female & $12(3 \mathrm{I} .6)$ \\
\hline Age & \\
$>58 . I$ & $18(47.4)$ \\
$<58 . I$ & $20(52.6)$ \\
\hline Smoking history & \\
Never & $12(31.6)$ \\
Current $>20$ years & $5(13.2)$ \\
$<20$ years & $2 \mathrm{I}(55.3)$ \\
\hline Adjuvant chemotherapy & \\
Yes & $14(36.8)$ \\
No & $24(63.2)$ \\
\hline Clinical stage & \\
I & $5(I 3.2)$ \\
II & $\mathrm{II}(28.9)$ \\
III & $18(47.4)$ \\
IV & $4(10.5)$ \\
\hline
\end{tabular}

were evaluated by two independent researchers, including an expert pathologist. The positive cells were counted and assigned with a score as follows: 1 ( $\leq 25 \%), 2(26 \% 50 \%)$, $3(51 \%-75 \%)$ and $4(>75 \%)$. The staining intensity was scored as: 1 (none), 2 (weak), 3 (intermediate), and 4 (strong). These scores were then multiplied to evaluate samples individually. The cut-off values were determined by the median value of the expression of each antibody for these three genes.

\section{Statistical Analysis}

All analyses were undertaken using SPSS ver. 11 (SPSS Inc., Chicago, IL, USA). The relationship of DLL3, CTLA-4, and MSTN expression with clinicopathologic findings was analyzed with a Chi-Square test. Kaplan-Meier curves and Cox model analyses were used to examine the relationship of DLL3, CTLA-4, and MSTN expression with patients' survival rate. Univariate and multivariate survival analysis were performed with the Cox proportional hazards model. Variables included in the Cox model included the following: age, gender, smoking status, and clinical TNM stages. Hazard ratio (HR) point and interval $(95 \% \mathrm{CI})$ estimates were computed through the Cox modeling. The two-sided log-rank and likelihood ratio statistics were calculated to test differences between Kaplan-Meier survival probabilities and death rates derived from the Cox regression, respectively. A $p<0.05$ was considered to be statistically significant.

\section{Results}

\section{Clinical Characteristics of the Research Cohort}

The study cohort included 26 male and 12 female patients, aged from 33 years to 77 years, with a median age of 58 years. Of these, 12 were non-smokers and 26 were current or former smokers. Twenty patients had tumors located in the left lung, and 18 had tumors located in the right lung. For pathological staging, the eighth TNM classification and staging system were used that released by the Union for International Cancer Control (UICC) in 2016. Table 1 shows the clinical characteristics of the cohort in detail.

\section{DLL3 Expression Status in the SCLC Patients}

Immunohistochemistry was used to analyze 38 cases of formalin-fixed paraffin-embedded (FFPE) tissue specimens from the SCLC patients. DLL3 was positively expressed in the cytoplasm and the nuclei of tumor cells, but the normal 
alveolar epithelial cells were negative. Positively stained tumor cells were found to be arranged in a prominent nesting pattern, and the nests were separated by delicate connective tissues (Figure 1). DLL3 positive expression was found in all 38 cases and, where the DLL3 score of the tumor was 13.5 or higher, were considered to have a high expression (present in 18 of 38 patients). DLL3 with high expression was found in 11 out of 20 (55\%) specimens from subjects older than 58 years, and in 9 out of $18(50 \%)$ cases 58 years or younger. DLL3 with high expression was found in 15 specimens out of $26(57.7 \%)$ in men and in 5 out of $12(41.7 \%)$ women. DLL3 with high expression was found in 9 out of $12(75 \%)$ specimens from nonsmokers and in 11 out of $26(42.3 \%)$ from smokers. DLL3 with high expression was found in 6 specimens out of 16 (37.5\%) from patients with disease stages I-II and14 out of $22(63.6 \%)$ patients with disease stages III-IV. DLL3 with high expression was found in specimens from 15 out of $23(65.2 \%)$ patients with metastasis and 5 out of 15 (33.3\%) patients without metastasis. Furthermore, the DLL3 staining status was analyzed for correlation with the clinical characteristics of the patients. The expression of DLL3 was not associated with the clinical characteristics of the patients, such as gender, age, smoking, clinical stages, and metastasis (Table 2).

\section{CTLA-4 Expression Status in the SCLC Patients}

CTLA-4 positive expression was found in 36 of out 38 $(89.5 \%)$ specimens and a CTLA-4 score of the tumor

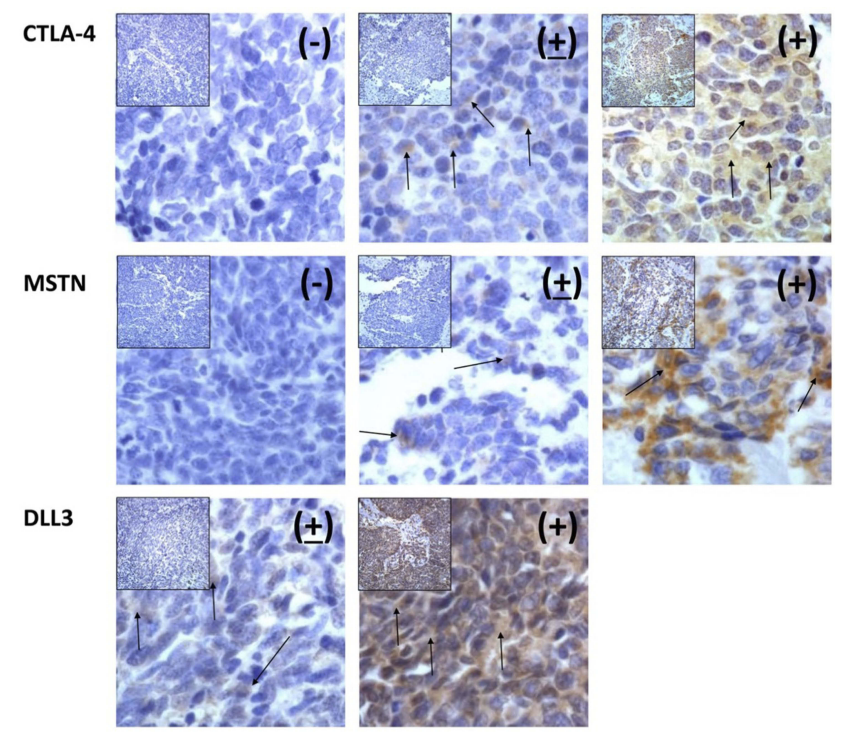

Figure I Immunohistochemical staining of CTLA-4, MSTN and DLL3 in SCLC tissues: $\times 400$. Positive $(+)$, partially positive $(+)$, and negative $(-)$.

Note: the arrows indicate the cells that are positive. greater than 8.2 was observed in 12 of 36 patients, and these patients were considered to have high expression. CTLA-4 with high expression was found in specimens from 7 out of $20(35 \%)$ patients older than 58 years and 5 out of $18(27.8 \%)$ patients of age 58 years or younger. CTLA-4 with high expression was found in specimens from 7 out of $26(26.9 \%)$ men and in 5 out of 12 (41.7) women. CTLA-4 with high expression was found in specimens from 3 out of $12(25 \%)$ non-smokers and in 9 out of $26(34.6 \%)$ smokers. CTLA-4 with high expression was found in specimens from 3 out of $16(18.8 \%)$ patients with disease stages I-II and in 9 out of $22(40.9 \%)$ patients with disease stages III-IV. CTLA-4 with high expression was found in specimens from 8 out of $23(34.8 \%)$ patients with metastasis and in 4 of $15(26.7 \%)$ patients without metastasis (Table 2). In addition, the CTLA-4 staining status was analyzed and compared with the clinical characteristics of the patients. The association study showed that CTLA-4 expression was not significantly associated with the clinical characteristics of the patients, such as gender, age, smoking status, clinical stages, and metastasis.

\section{MSTN Expression in the SCLC Patients}

MSTN positive expression was found in 31 out of 38 (81.5\%) specimens and an MSTN expression score greater than 5.3 was observed in 11 of 31 patients, and these patients were considered to have high expression. High MSTN expression was found in 8 out of $20(40 \%)$ specimens from patients older than 58 years, and in 3 out of 18 (16.7\%) patients aged 58 years or younger. High MSTN expression was found in 8 out of $20(40 \%)$ specimens from patients older than 58 years and in 3 out of $18(16.7 \%)$ patients aged 58 years or younger. MSTN with high expression was found in 4 out of $12(33.3 \%)$ specimens from non-smokers and in 7 out of $26(24.9 \%)$ from smokers. MSTN with high expression was found in 4 out of $16(25 \%)$ specimens from patients with disease stages I-II and 7 out of $22(31.8 \%)$ patients with stages III-IV. MSTN with high expression was found in 5 out of $23(43.5 \%)$ specimens from patients with metastasis and in 6 out of $15(40 \%)$ patients without metastasis (Table 2). The MSTN staining status was compared with the clinical characteristics of the patients and the MSTN expression was found not to be significantly associated with the other clinical characteristics of the patients, such as smoking status, clinical stage, and metastasis.

Additionally, from Table 2, it appears that the expression of DLL3 was higher in those patients with stage III-IV (63.6\% vs $36.4 \%$ ), whereas the expression of CTLA-4 and MSTN in 
Table 2 Correlation of DLL3, CTLA-4 and MSTN Expression with Clinicopathological Characteristics

\begin{tabular}{|c|c|c|c|c|c|c|c|c|c|c|}
\hline \multirow[t]{2}{*}{ Factors } & \multirow[t]{2}{*}{ №\% } & \multicolumn{3}{|c|}{ DLL3 Expression } & \multicolumn{3}{|c|}{ CTLA-4 Expression } & \multicolumn{3}{|c|}{ Mesothelin Expression } \\
\hline & & Low & High & P Value & Low & High & P Value & Low & High & P Value \\
\hline Total & $N=38$ & I8(47.4) & $20(52.6)$ & & $26(68.4)$ & $12(31.6)$ & & $27(7 I .1)$ & II(28.9) & \\
\hline $\begin{array}{l}\text { Gender } \\
\text { Male } \\
\text { Female }\end{array}$ & $\begin{array}{l}26(68.4) \\
12(31.6)\end{array}$ & $\begin{array}{l}\text { I I(42.3) } \\
7(58.3)\end{array}$ & $\begin{array}{l}\text { I5(57.7) } \\
5(4 \mid .7)\end{array}$ & 0.489 & $\begin{array}{l}19(73.1) \\
7(58.3)\end{array}$ & $\begin{array}{l}7(26.9) \\
5(41.7)\end{array}$ & 0.460 & $\begin{array}{l}19(73.1) \\
8(66.7)\end{array}$ & $\begin{array}{l}7(26.9) \\
4(33.3)\end{array}$ & 0.714 \\
\hline $\begin{array}{l}\text { Age } \\
\qquad 58 \\
>58\end{array}$ & $\begin{array}{l}18(47.4) \\
20(52.6)\end{array}$ & $\begin{array}{l}9(50) \\
9(45)\end{array}$ & $\begin{array}{l}9(50) \\
I I(55)\end{array}$ & 1.000 & $\begin{array}{l}13(72.2) \\
13(65)\end{array}$ & $\begin{array}{l}5(27.8) \\
7(35)\end{array}$ & 0.734 & $\begin{array}{l}15(58.3) \\
12(60)\end{array}$ & $\begin{array}{l}3(16.7) \\
8(40)\end{array}$ & 0.160 \\
\hline $\begin{array}{l}\text { Smoking status } \\
\text { Never } \\
\text { Ever }\end{array}$ & $\begin{array}{l}12(31.6) \\
26(68.4)\end{array}$ & $\begin{array}{l}3(25) \\
15(57.7)\end{array}$ & $\begin{array}{l}9(75) \\
\text { II(42.3) }\end{array}$ & 0.086 & $\begin{array}{l}9(75) \\
17(65.4)\end{array}$ & $\begin{array}{l}3(25) \\
9(34.6)\end{array}$ & 0.714 & $\begin{array}{l}8(66.7) \\
19(73.1)\end{array}$ & $\begin{array}{l}4(33.3) \\
7(24.9)\end{array}$ & 0.714 \\
\hline $\begin{array}{l}\text { Clinical stage } \\
\text { I-II } \\
\text { III-IV }\end{array}$ & $\begin{array}{l}16(42.1) \\
22(57.9)\end{array}$ & $\begin{array}{l}10(62.5) \\
8(36.4)\end{array}$ & $\begin{array}{l}6(37.5) \\
14(63.6)\end{array}$ & 0.188 & $\begin{array}{l}13(81.3) \\
13(59.1)\end{array}$ & $\begin{array}{l}3(18.8) \\
9(40.9)\end{array}$ & 0.178 & $\begin{array}{l}12(75) \\
15(68.2)\end{array}$ & $\begin{array}{l}4(25) \\
7(31.8)\end{array}$ & 0.729 \\
\hline $\begin{array}{l}\text { Metastasis status } \\
\text { Yes } \\
\text { No }\end{array}$ & $\begin{array}{l}23(60.5) \\
15(39.5)\end{array}$ & $\begin{array}{l}8(34.8) \\
10(66.7)\end{array}$ & $\begin{array}{l}15(65.2) \\
5(33.3)\end{array}$ & 0.096 & $\begin{array}{l}\text { I5(65.2) } \\
\text { II(73.3) }\end{array}$ & $\begin{array}{l}8(34.8) \\
4(26.7)\end{array}$ & 0.728 & $\begin{array}{l}18(78.3) \\
9(60)\end{array}$ & $\begin{array}{l}5(21.7) \\
6(40)\end{array}$ & 0.285 \\
\hline
\end{tabular}

patients with stage III-IV was $40.9 \%$ vs $50.1 \%$, and $31.8 \%$ vs $68.2 \%$, respectively. However, these differences were not significant, which may present difficulty in establishing a negative correlation among these three-gene expressions.

\section{The Expression Status of DLL3, CTLA-4, and MSTN with a Prognosis of SCLC Patients}

As of January 2015, complete prognosis data was available for 29 patients, including 4 cases of death and 25 cases of survival. The median period of patient follow-up for the entire series was 39.8 months (range from 7 months to 72 months). As shown in Figure 2 and Table 3, we conducted a survival analysis of these 29 patients with respect to the presence of DLL3, CTLA-4, and MSTN expression. We found that the median survival time of those patients with DLL3 with high expression was 12 months (range from 1 month to 43 months); for those patients with DLL3 low expression, it was 23 months (range from 6 months to 44 months). Furthermore, DLL3 with high expression showed a poorer prognosis than DLL3 with low expression. The difference in median overall survival times between these two groups was statistically significant $(\mathrm{HR}=3.12$; $95 \% \mathrm{CI}$, 0.99-9.82; $\mathrm{p}=0.000)$. We may therefore, infer with $95 \%$
A

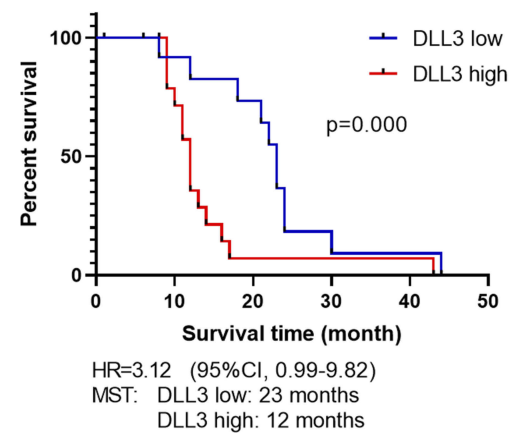

B

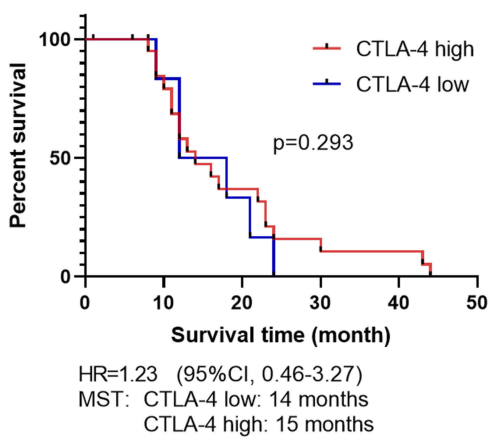

C

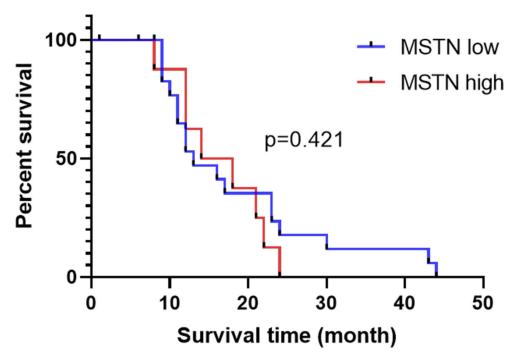

$\mathrm{HR}=1.71 \quad(95 \% \mathrm{Cl}, 0.53-5.47)$ MST: MSTN low: 13 months MSTN high: 15 months

Figure 2 Overall survival study: (A) Kaplan Meier curves for all patients stratified according to the DLL3 expression, (B) Kaplan Meier curves for all patients stratified according to the CTLA-4 expression, (C) Kaplan Meier curves for all patients stratified according to the MSTN expression. 
Table 3 Univariate and Multivariate Analysis of the Prognostic Factors on OS in Patients with SCLC

\begin{tabular}{|c|c|c|c|c|c|c|}
\hline \multirow[t]{2}{*}{ Characteristics } & \multicolumn{3}{|c|}{ Univariate Analysis } & \multicolumn{3}{|c|}{ Multivariate Analysis } \\
\hline & MST(m) & SD & $\mathbf{P}$ & HR & $95 \% \mathrm{Cl}$ & $\mathbf{P}$ \\
\hline Gender & & & 0.069 & 0.34 & $0.11-1.04$ & 0.014 \\
\hline Male & 12.5 & 8.34 & & & & \\
\hline Female & 18.5 & 10.85 & & & & \\
\hline Age & & & 0.593 & 0.87 & $0.33-2.3$ & 0.216 \\
\hline$<58$ & 15.28 & 11.95 & & & & \\
\hline$>58$ & 13.6 & 6.7 & & & & \\
\hline Smoking status & & & 0.725 & 1.16 & $0.44-3.02$ & 0.000 \\
\hline Never & 14.77 & 10.9 & & & & \\
\hline Ever & 13.58 & 5.4 & & & & \\
\hline Clinical stage & & & 0.381 & 0.81 & $0.29-2.27$ & 0.016 \\
\hline I-II & 16 & 7.5 & & & & \\
\hline III-IV & 13.23 & 10.7 & & & & \\
\hline Metastasis status & & & 0.068 & 1.31 & $0.49-3.46$ & 0.698 \\
\hline Yes & 12.13 & 6.3 & & & & \\
\hline No & 17.87 & 12.39 & & & & \\
\hline DLL3 & & & 0.102 & 3.12 & $0.99-9.82$ & 0.000 \\
\hline High & 12.00 & 8.16 & & & & \\
\hline Low & 23.01 & 10.35 & & & & \\
\hline CTLA-4 & & & 0.146 & 1.23 & $0.46-3.27$ & 0.293 \\
\hline High & 15.00 & 6.71 & & & & \\
\hline Low & 13.99 & 10.2 & & & & \\
\hline MSTN & & & 0.786 & 1.71 & $0.53-5.47$ & 0.421 \\
\hline High & $15.0 \mid$ & 6.6 & & & & \\
\hline Low & 13.00 & 10.5 & & & & \\
\hline
\end{tabular}

confidence that the death rate from DLL3 with high expression is higher than the risk from DLL3 at low expression.

In the case of the patients with CTLA-4 with high expression, their median survival time was 15 months (range from 1 month to 24 months); while those patients with CTLA-4 at low expression showed a median survival of 14 months (range from 6 months to 44 months). The difference in median overall survival times between these two groups was not statistically significant $(\mathrm{HR}=1.23 ; 95 \%$ CI, 0.46-3.27; $\mathrm{p}=0.293$ ).

In the case of the patients with MSTN with high expression, the median survival time was 15 months (range from 6 months to 24 months); those patients with MSTN at low expression had a median survival time of 13 months (range from 1 month to 44 months). The difference in median overall survival times between these two groups was not statistically significant $(\mathrm{HR}=1.71 ; 95 \% \mathrm{CI}, 0.53-5.47 ; \mathrm{p}=0.421)$.
Furthermore, the patients' characteristics were evaluated to determine their prognostic value for OS (Table 3). Multivariate analysis revealed that the gender, smoking status, clinical stage, and expression level of DLL3 were independent favorable OS prognostic factors.

\section{Discussion}

SCLC is an aggressive disease characterized by rapid tumor growth and early metastatic dissemination. ${ }^{22}$ The primary etiologic agent responsible for SCLC, associated with both lung cancer carcinogenesis and the prognosis of lung cancer patients, is considered to be smoking. ${ }^{23}$ In general, between 2 and11.5\% of patients diagnosed with SCLC are non-smokers, ${ }^{23-25}$ however in our study, $36.3 \%$ of patients had no apparent history of smoking. However, because it was a retrospective study and there were some confounding variables, such as second-hand or third-hand tobacco exposure, they were not able to consider in this 
research. The survival rate for SCLC is extremely low and essentially has not changed over the past 30 years. ${ }^{26}$ However, in recent years, effective strategies have been developed to treat SCLC, such as antibody-drug conjugate or ADC-technology, recognition of appropriate target antigens, novel monoclonal antibodies (mAbs), and immune targets.

In this study, we examined the DLL3 expression in a Chinese SCLC population and confirmed that DLL3 was $100 \%(38 / 38)$ positively expressed in those patients, a similar finding to that of a recent TRINITY trial. ${ }^{27}$ DLL3 expression was also evaluated in studies of Japanese SCLC patients and DLL3 high expression was found to be $83 \%(52 / 62)^{28}$ and $90 \%(18 / 20) .{ }^{29}$ We also investigated the correlation between DLL3 expression, patient characteristics and clinical outcomes in SCLC. A significant finding of this study was that DLL3 with high expression is correlated with poorer patient outcomes, a result similar to that of the phase I clinical trials of Rova-T which evaluated DLL3 expression in recurrent SCLC. ${ }^{9}$ However, we found no correlation between DLL3 expression and other patient characteristics. Table 4 shows the review of the studies of DLL3 expression in lung cancer. In a first-in-human, first-in-class, open-label phase I study, Rova-T (rovalpituzumab tesirine), a DLL3 target, has shown promise. ${ }^{9}$ After Rova $\mathrm{T}$ treatment, overall survival was 4.6 months. In an exploratory analysis, in those with DLL3-high expression, median overall survival was 5.8 months and in those with DLL3-low expression, median overall survival was 2.7 months. Median progression survival was 4.3 months and 2.2 months, respectively. ${ }^{9}$ Liu and collaborators further explored correlations between DLL3 expression and clinicopathologic features in highgrade pulmonary neuroendocrine carcinomas, including SCLC and found that 210 of 335 SCLC patients $(63 \%)$ showed a high DLL3 expression. Low DLL3 expression was also related to a longer OS, although this was not statistically significant $(p=0.077) .^{30}$ In a study of 63 Japanese patients, which evaluated the correlation between DLL3 expression and patient characteristics, no significant correlation was found between DLL3 expression and age, sex, smoking history, disease stage or biopsy site. Furthermore, the DLL3 expression status was not found to be correlated to prognosis. ${ }^{28}$ In the single-arm, phase II TRINITY trial investigating Rova-T in a third-line treatment setting for patients with relapsed/refractory SCLC, the objective response rate (ORR) was $16 \%$ in the DLL3high group and $6 \%$ in the DLL3-low group. The clinical benefit rate was $24 \%$ and $14 \%$, respectively. ${ }^{27}$ The phase III TAHOE trial (NCT03061812) has now been evaluated;

Table 4 Studies of DLL3 Immunohistochemistry

\begin{tabular}{|c|c|c|c|c|}
\hline Tumor Type & $\begin{array}{l}\text { Positive } \\
\%\end{array}$ & $\mathbf{N}$ & Correlation With Survival & Reference \\
\hline Small cell lung cancer & $88 \%$ & $42 / 48$ & $\begin{array}{l}\text { High expression, mPFS } 4.3 \text { months ( } 95 \% \mathrm{Cl}, 2.8-5.6) \text {; Low expression, } \\
\text { mPFS } 2.2 \text { months ( } 95 \% \mathrm{Cl}, 1.3-2.5 \text { ) (after Rova-T treatment) }\end{array}$ & Rudin $2017^{9}$ \\
\hline Small cell lung cancer & $82.5 \%$ & $52 / 63$ & No significant association $(p=0.943)$ & Tanaka $2018^{28}$ \\
\hline Small cell lung cancer & $90 \%$ & $18 / 20$ & NE & Saito $2017^{29}$ \\
\hline Small cell lung cancer & $72 \%$ & $120 / 167$ & NE & Saunders $2015^{33}$ \\
\hline Small cell lung cancer & NA & & Low DLL3 expression related to a longer OS $(p=0.077)$ & Liu $2017^{30}$ \\
\hline Small cell lung cancer & $100 \%$ & $339 / 339$ & $\begin{array}{l}\text { High expression mOS } 5.7 \text { months, in all pts mOS } 5.6 \text { months } \\
\text { (after Rova-T treatment) }\end{array}$ & Carbone $2018^{27}$ \\
\hline Small cell lung cancer & $100 \%$ & $38 / 38$ & DLL3 high expression associated with poorer outcomes $(p=0.01)$ & Current study \\
\hline Small cell bladder cancer & $68 \%$ & $36 / 53$ & DII3 high expression associated with poor outcomes $(p=0.01)$ & Koshkin $2017^{34}$ \\
\hline LCNEC & $65 \%$ & $37 / 57$ & NE & Saunders $2015^{33}$ \\
\hline Lung adenocarcinoma & $3.7 \%$ & $3 / 82$ & NE & Saunders $2015^{33}$ \\
\hline $\begin{array}{l}\text { Gastrointestinal } \\
\text { neuroendocrine tumor }\end{array}$ & $100 \%$ & $9 / 9$ & NE & Zhang $2017^{35}$ \\
\hline
\end{tabular}

Abbreviations: LCNNEC, large cell neuroendocrine carcinoma; mPFS, median progression-free survival; NE, not evaluated; NA, not available. 
this compared Rova-T with topotecan in patients with advanced or metastatic SCLC with high levels of DLL3, who experienced their first disease progression during, or following, frontline platinum-based chemotherapy. Disappointingly, in our view, the independent data monitoring committee (in accordance with AbbVie) has stopped further enrollment in the TAHOE trial on basis of the shorter OS reported in the Rova-T arm compared to the control arm. ${ }^{31}$ However, additional Rova-T clinical trials are ongoing and are recruiting participants; including a phase III MERU study (NCT03033511), which is an ongoing trial investigating Rova-T as maintenance therapy to follow first-line platinum-based chemotherapy in patients with advanced stage SCLC. A phase I open-label study, currently active, is also comparing the combination of Rova-T with nivolumab and with or without ipilimumab in adults with advanced stage SCLC who have had first disease progression during at least one platinum-based chemotherapeutic regimen (NCT03026166). ${ }^{32}$ Several published studies have evaluated the DLL3 expression occurring in different tumor types, and some of these have investigated the correlation between DLL3 expression and patient characteristics and clinical outcomes. ${ }^{33-35}$ For example, a retrospective study showed that DLL3 high expression had a significant correlation with poorer patient outcomes in small cell bladder cancer (SCBC). ${ }^{34}$ These studies showed that patients with a higher DLL3 expression in SCLC and SCBC had a poorer prognosis than those with a low expression, suggesting DLL3 as a promising target for tumor ADCs.

In this study, we evaluated CTLA-4 expression in a Chinese SCLC population and confirmed that CTLA-4 is $89.5 \%$ (36/38) positively expressed in these patients. To the best of our knowledge, this retrospective study represents the first investigation of CTLA-4 expression in SCLC. In our study cohort, we found no significant correlation of CTLA-4 expression with patient characteristics and clinical outcomes in SCLC. As shown in Table 5, in the past, many researchers have evaluated CTLA-4 expression in different tumor types. $^{36-42}$ For example, a recent study found CTLA-4

Table 5 Studies of CTLA-4 Immunohistochemistry

\begin{tabular}{|c|c|c|c|c|}
\hline Tumor Type & $\begin{array}{l}\text { Positive } \\
\%\end{array}$ & $\mathbf{N}$ & Correlation With Survival & Reference \\
\hline Small cell lung cancer & $89.5 \%$ & $36 / 38$ & Not associated with OS $(p=0.656)$ & Current study \\
\hline NSCLC & $50.6 \%$ & $4 I / 8 I$ & $\begin{array}{l}\text { CTLA- } 4 \text { over-expression tended to have a better prognostic impact } \\
\text { than lower expression ( } 5 \text {-year probability: } 64.8 \text { vs } 45.9 \% ; p=0.079 \text { ) }\end{array}$ & Salvi $2012^{38}$ \\
\hline $\begin{array}{l}\text { NSCLC (PTs) } \\
\text { SCC (s-CTLA4) } \\
(\mathrm{t}-\mathrm{CTLA}-4) \\
\text { ADC (s-CTLA-4) } \\
\quad(\mathrm{t}-\mathrm{CTLA}-4) \\
\text { LN+ } \\
\text { SCC (t-CTLA-4) } \\
\text { ADC (t-CTLA-4) }\end{array}$ & $\begin{array}{l}47 \% \\
37 \% \\
44 \% \\
42 \% \\
\\
24 \% \\
38 \%\end{array}$ & $\begin{array}{l}536 \\
136 / 287 \\
107 / 289 \\
84 / 196 \\
85 / 192 \\
\\
18 / 75 \\
22 / 58\end{array}$ & $\begin{array}{l}\text { High expression of t-CTLA-4 associated with poor outcomes in LN+ } \\
\text { group. CTLA-4 expression was not associated with poor outcomes in } \\
\text { PTs group. }\end{array}$ & Paulsen $2017^{36}$ \\
\hline $\begin{array}{l}\text { Malignant pleural } \\
\text { mesothelioma }\end{array}$ & $56.1 \%$ & $23 / 41$ & $\begin{array}{l}\text { Favorable prognostic factor (but not significant) } \mathrm{HR}=0.57 ; 95 \% \mathrm{Cl} \text {, } \\
0.28-1.20\end{array}$ & Roncella $2016^{39}$ \\
\hline Osteosarcoma & $100 \%$ & $6 / 6$ & NE & Contardi $2005^{37}$ \\
\hline Breast tumor & $100 \%$ & $5 / 5$ & & \\
\hline Breast carcinoma & $100 \%$ & $60 / 60$ & $\begin{array}{l}\text { High CTLA- } 4 \text { expression tended to have a better prognosis than } \\
\text { lower expression }\end{array}$ & Mao $2010^{40}$ \\
\hline Melanoma & $40 \%$ & $8 / 20$ & NE & Laurent $2013^{41}$ \\
\hline $\begin{array}{l}\text { Nasopharyngeal } \\
\text { carcinoma }\end{array}$ & $97.4 \%$ & $186 / 191$ & High expression associated with poorer outcomes $(p=0.044)$ & Huang $2016^{42}$ \\
\hline
\end{tabular}

Abbreviations: NSCLC, non-small cell lung cancer; OS, overall survival; HR, hazard ratio; SCC, squamous cell carcinoma, ADC, adenocarcinoma; LN+, metastatic lymph nodes; S, stromal; T, tumor epithelial, PT, primary tumor; NE, not evaluated. 
Table 6 Studies of MSTN Immunohistochemistry

\begin{tabular}{|c|c|c|c|c|}
\hline Tumor Type & $\begin{array}{l}\text { Positive } \\
\%\end{array}$ & $\mathbf{N} *$ & Correlation With Survival & Reference \\
\hline Small cell lung cancer & $81.5 \%$ & $31 / 38$ & Not associated with OS $(p=0.582)$ & Current study \\
\hline Lung adenocarcinoma & $41 \%$ & $14 / 34$ & NE & Ordonez $2003^{45}$ \\
\hline Lung adenocarcinoma & $53 \%$ & $49 / 93$ & High mesothelin expression associated with poor survival $(p=0.014)$ & Thomas $2015^{46}$ \\
\hline Lung adenocarcinoma & $69 \%$ & $834 / 1209$ & High mesothelin expression associated with poor survival $(p<0.0 \mathrm{l})$ & Kachala $2014^{47}$ \\
\hline $\begin{array}{l}\text { Lung squamous } \\
\text { carcinoma }\end{array}$ & $28 \%$ & $5 / 23$ & \multirow[t]{2}{*}{ NE } & \multirow[t]{2}{*}{ Ordonez $2003^{45}$} \\
\hline $\begin{array}{l}\text { Ovarian serous } \\
\text { carcinoma }\end{array}$ & $100 \%$ & $14 / 14$ & & \\
\hline $\begin{array}{l}\text { Ovarian serous } \\
\text { adenocarcinoma }\end{array}$ & $55 \%$ & $109 / 198$ & NE & Bauerschlag $2013^{64}$ \\
\hline $\begin{array}{l}\text { Ovarian serous } \\
\text { carcinoma }\end{array}$ & $55 \%$ & $92 / 167$ & $\begin{array}{l}\text { Diffuse MSTN expression is associated with prolonged patient } \\
\text { survival }(p=0.023)\end{array}$ & Yen $2006^{48}$ \\
\hline Ovarian carcinoma & 96 & $24 / 25$ & NE & Weekes $2018^{61}$ \\
\hline Ovarian cancer & $70 \%$ & $47 / 67$ & NE & Frierson $2003^{18}$ \\
\hline Ovarian cancer & $75 \%$ & $3 / 4$ & NE & Lamberts $2016^{57}$ \\
\hline Breast carcinoma & $3 \%$ & $1 / 35$ & NE & Ordonez $2003^{45}$ \\
\hline Breast carcinoma & $67 \%$ & $29 / 43$ & NE & Tchou $2012^{59}$ \\
\hline Breast carcinoma & $78.6 \%$ & $22 / 28$ & \multirow[t]{2}{*}{ NE } & \multirow[t]{2}{*}{ Ordonez $2014^{63}$} \\
\hline TNBC & $39.6 \%$ & $21 / 53$ & & \\
\hline TNBC & $34 \%$ & $37 / 109$ & $\begin{array}{l}\text { MSTN expression was not independent predictor of survival } \\
(p=0.57)\end{array}$ & Parinyanitikul $2013^{54}$ \\
\hline TNBC & $36 \%$ & $82 / 226$ & \multirow[t]{2}{*}{ Correlated with poor survival $(p=0.0003)$} & \multirow[t]{2}{*}{ Tozbikian $2017^{60}$} \\
\hline Non-TNBC & $16 \%$ & $14 / 88$ & & \\
\hline Mesothelioma & $60 \%$ & $60 / 100$ & NE & Ordonez $2014^{63}$ \\
\hline Teratoma & $100 \%$ & $2 / 2$ & \multirow[t]{2}{*}{ NE } & \multirow[t]{2}{*}{ Ordonez $2003^{45}$} \\
\hline Cholangiocarcinoma & $37 \%$ & $7 / 19$ & & \\
\hline $\begin{array}{l}\text { Extrahepatic bile duct } \\
\text { adenocarcinoma }\end{array}$ & $50 \%$ & $5 / 10$ & NE & Zhao $2007^{62}$ \\
\hline $\begin{array}{l}\text { Extrahepatic bile duct } \\
\text { cancer }\end{array}$ & $47.5 \%$ & $29 / 61$ & $\begin{array}{l}\text { High level expression was significantly correlated with poorer } \\
\text { patient outcomes }(p=0.022)\end{array}$ & Kawamata $2012^{53}$ \\
\hline $\begin{array}{l}\text { Pancreatico-biliary } \\
\text { adenocarcinoma }\end{array}$ & $73 \%$ & $72 / 99$ & NE & Ali $2014^{58}$ \\
\hline $\begin{array}{l}\text { Pancreatic ductal } \\
\text { adenocarcinoma }\end{array}$ & $86 \%$ & $12 / 14$ & & Ordonez $2003^{45}$ \\
\hline $\begin{array}{l}\text { Pancreatic ductal } \\
\text { adenocarcinoma }\end{array}$ & $39.8 \%$ & $41 / 103$ & $\begin{array}{l}\text { Co-expression of MSTN and MUCI6 (high levels for both) was } \\
\text { associated with poor prognosis }(p=0.0006)\end{array}$ & Shimizu $2012^{55}$ \\
\hline
\end{tabular}


Table 6 (Continued).

\begin{tabular}{|c|c|c|c|c|}
\hline Tumor Type & $\begin{array}{l}\text { Positive } \\
\%\end{array}$ & $\mathbf{N *}$ & Correlation With Survival & Reference \\
\hline $\begin{array}{l}\text { Pancreatic ductal } \\
\text { adenocarcinoma }\end{array}$ & $86.4 \%$ & $57(66)$ & $\begin{array}{l}\text { Co-expression of MSTN and CAI } 25 \text { were associated with an } \\
\text { unfavorable patient outcome }(p=0.0062)\end{array}$ & Einama $201 I^{52}$ \\
\hline Pancreatic cancer & $83 \%$ & $25 / 30$ & NE & Weekes $2016^{61}$ \\
\hline Pancreatic cancer & $42.8 \%$ & $3 / 7$ & NE & Lamberts $2016^{57}$ \\
\hline Pancreatic cancer & $70.8 \%$ & $97 / 137$ & $\begin{array}{l}\text { MSTN and MUCI expression are highly significant predictors of } \\
\text { early cancer-specific mortality }(p<0.000 \mathrm{I})\end{array}$ & Winter $2012^{56}$ \\
\hline $\begin{array}{l}\text { Esophageal } \\
\text { adenocarcinoma }\end{array}$ & $25 \%$ & $\mathrm{I} / 4$ & & Ordonez $2003^{45}$ \\
\hline $\begin{array}{l}\text { Esophageal squamous } \\
\text { carcinoma }\end{array}$ & $75 \%$ & $3 / 4$ & & \\
\hline Gastric cancer & $58 \%$ & $29 / 50$ & & Ito $2014^{51}$ \\
\hline Gastric cancer & $44.5 \%$ & $49 / 110$ & Poor prognostic factor $(p=0.0073)$ & Einama $2011^{52}$ \\
\hline Gastric cancer & $59 \%$ & $73 / 124$ & Correlated with prolonged survival $(p=0.0628)$ & Baba $2012^{49}$ \\
\hline $\begin{array}{l}\text { Gastric } \\
\text { adenocarcinoma }\end{array}$ & $29 \%$ & $2 / 7$ & NE & Ordonez $2003^{45}$ \\
\hline $\begin{array}{l}\text { Gastric } \\
\text { adenocarcinoma }\end{array}$ & $50.4 \%$ & $64 / 127$ & NE & Illei $2016^{50}$ \\
\hline $\begin{array}{l}\text { Cervical squamous } \\
\text { carcinoma }\end{array}$ & $25 \%$ & $1 / 4$ & NE & Ordonez $2003^{45}$ \\
\hline Adenomatoid tumor & $100 \%$ & $3 / 3$ & & \\
\hline $\begin{array}{l}\text { Endometroid uterine } \\
\text { adenocarcinoma }\end{array}$ & $64 \%$ & $7 / 11$ & & \\
\hline $\begin{array}{l}\text { Endometroid uterine } \\
\text { adenocarcinoma }\end{array}$ & $59 \%$ & $13 / 22$ & NE & Frierson $2003^{18}$ \\
\hline $\begin{array}{l}\text { Adenocarcinoma- } \\
\text { ampulla of Vater }\end{array}$ & $100 \%$ & $3 / 3$ & NE & Ordonez $2003^{45}$ \\
\hline $\begin{array}{l}\text { Laryngeal squamous } \\
\text { carcinoma }\end{array}$ & $100 \%$ & $1 / 1$ & & \\
\hline $\begin{array}{l}\text { Desmoplastic small } \\
\text { round cell tumor }\end{array}$ & $58 \%$ & $7 / 12$ & & \\
\hline $\begin{array}{l}\text { Colorectal } \\
\text { adenocarcinoma }\end{array}$ & $49.5 \%$ & $45 / 91$ & $\begin{array}{l}\text { High level expression is not correlated with OS compared to low } \\
\text { level expression }(p=0.26)\end{array}$ & Kawamata $2012^{53}$ \\
\hline
\end{tabular}

Note: *N:number.

Abbreviations: TNBC, triple-negative breast carcinoma; OS, overall survival; NE, not evaluated.

overexpression in $47 \%$ of 536 patients with NSCLC. ${ }^{36}$ Interestingly, CTLA-4 overexpression tended to have a better prognostic impact than lower expression in NSCLC, ${ }^{38}$ breast cancer, and malignant pleural mesothelioma. ${ }^{39}$ Targeted immunotherapies involving
CTLA-4 and PD1/PD-L1 checkpoint pathways have shown promise as effective and safe therapies in patients with SCLC, NSCLC and melanoma, as demonstrated by the durable objective responses and overall survival rates achieved with these agents. ${ }^{43,44}$ Additional clinical trials of 
ipilimumab are ongoing and are actively recruiting participants, including a phase II study of patients with SCLC treated with combination immunotherapy-ipilimumabnivolumab-dendritic cell p53 Vac, who have had recurrence of disease following at least one platinum-based chemotherapeutic regimen (NCT03406715). ${ }^{32}$

In this study, we examined the MSTN expression in a Chinese SCLC population and confirmed that MSTN is $81.5 \%(31 / 38)$ positively expressed in these patients. To the best of our knowledge, the determination of MSTN expression by IHC staining in SCLC patients has not been previously undertaken. We found no significant correlation between MSTN expression and patient characteristics and clinical outcomes in SCLC. As shown in Table 6, several published studies have evaluated MSTN expression in different tumor types. ${ }^{18,20,45-64}$ For example, a recent retrospective study found MSTN expression in 41-69\% cases of lung adenocarcinoma, ${ }^{45-47}$ and high MSTN expression associated with poor survival in these patients. ${ }^{46,47}$ Similarly, in triple-negative breast cancer (TNBC) and in extrahepatic bile duct cancer, high MSTN expression has been shown to be associated with a poor prognosis. ${ }^{60,62}$ But in ovarian serous cancer, diffuse MSTN expression was associated with prolonged patient survival. ${ }^{48}$ The expression of MSTN has been observed and studied in many types of cancer, but particularly in the case of SCLC, further studies are necessary. Currently, several agents that target MSTN expressing tumors are being investigated in clinical trials, including SS1P (anti-MSTN immunotoxin), amatuximab (MORAb009, a high-affinity chimeric monoclonal immunoglobulin G1/k antibody), anti-MSTN antibody-drug conjugate anetumabravtansine (BAY94-9343), and a MSTN tumor vaccine (CRS-207) as well as a MSTN adoptive T-cell immunotherapy using MSTN-specific chimeric antigen receptors. ${ }^{35}$ To our knowledge, there are no clinical trials in the field of SCLC currently being undertaken.

\section{Conclusion}

We have studied DLL3, CTLA-4, and MSTN expression in SCLC and propose that DLL3 expressions in SCLC might be a promising prognostic markers for patients. In addition, it has been hypothesized that high expressions of DLL3, CTLA-, and MSTN in SCLC play a significant role in tumor pathogenesis. In this study, we found that the levels of expression of DLL3, CTLA-4, and MSTN are were not correlated with clinical characteristics in SLCL, but the precise roles of DLL3, CTLA-4, and MSTN in SCLC development remain unclear and require further investigation.

\section{Ethics Approval and Consent to Participate}

This study was conducted in accordance with the Declaration of Helsinki and was approved by the Ethical Review Committee of Tianjin Medical University General Hospital. All biological samples and relevant clinical information were obtained with patients' written informed consent.

\section{Availability of Data and Materials}

Data sharing not applicable to this article as no datasets were generated or analyzed during the current study.

\section{Acknowledgements}

We thank BioMed Proofreading LLC for the Englishlanguage editing.

\section{Author Contributions}

JC and HYL designed and supervised of the study. OR, HYL and JC wrote the manuscript. OR and YL performed the experiments. YWL, HBZ, HG, YY, JW and WTL helped to perform some experiments. All authors contributed to data analysis, drafting and revision of the article, gave approval of the final draft to be published, and agree to be accountable for all aspects of the work.

\section{Funding}

This work was supported by grants from the National Natural Science Foundation of China (81773207, 81372306) and the Natural Science Foundation of Tianjin (17YFZCSY00840, 18PTZWHZ00240, 19YFZCSY00040), and the Special Support Program for High Tech Leader \& Team of Tianjin (TJTZJH-GCCCXCYTD-2-6). Funding had no any role on the study design, data collection, analysis and interpretation, or writing of the manuscript.

\section{Disclosure}

The authors report no conflicts of interest in this work.

\section{References}

1. Bray F, Ferlay J, Soerjomataram I, Siegel RL, Torre LA, Jemal A. Global cancer statistics 2018: GLOBOCAN estimates of incidence and mortality worldwide for 36 cancers in 185 countries. CA Cancer J Clin. 2018;68(6):394-424. doi:10.3322/caac.v68.6

2. van Meerbeeck JP, Fennell DA, De Ruysscher DK. Small-cell lung cancer. Lancet. 2011;378(9804):1741-1755. doi:10.1016/S01406736(11)60165-7

3. Kalemkerian GP, Akerley W, Bogner P, et al. Small cell lung cancer. J Natl Compr Canc Netw. 2013;11(1):78-98. doi:10.6004/ jncen.2013.0011 
4. Karachaliou N, Pilotto S, Lazzari C, Bria E, de Marinis F, Rosell R. Cellular and molecular biology of small cell lung cancer: an overview. Transl Lung Cancer Res. 2016;5(1):2-15. doi:10.3978/j. issn.2218-6751.2016.01.02

5. https://immuno-oncologynews.com/2018/08/21/immunotherapy-opdivofda-approved-some-small-cell-lung-cancer-patients/. Accessed Septem ber $11,2018$.

6. Wang C, Thudium KB, Han M, et al. In vitro characterization of the anti-PD-1 antibody nivolumab, BMS-936558, and in vivo toxicology in non-human primates. Cancer Immunol Res. 2014;2(9):846-856. doi:10.1158/2326-6066.CIR-14-0040

7. https://www.onclive.com/web-exclusives/fda-approves-atezolizumabregimen-for-frontline-small-cell-lung-cancer. Accessed April 5, 2019.

8. Horn L, Mansfield AS, Szczęsna A, et al. First-line atezolizumab plus chemotherapy in extensive-stage small-cell lung cancer. $N$ Engl $J$ Med. 2018;379(23):2220-2229. doi:10.1056/NEJMoa1809064

9. Rudin CM, Pietanza MC, Bauer TM, et al. Rovalpituzumab tesirine, a DLL3-targeted antibody-drug conjugate, in recurrent small-cell lung cancer: a first-in-human, first-in-class, open-label, phase 1 study. Lancet Oncol. 2017;18(1):42-51. doi:10.1016/S1470-2045(16)30565-4

10. Kavalerchik E, Lally S, Han TH, Saunders LR, Bheddah S, Dylla SJ. An open-label study of rovalpituzumab tesirine in patients with DLL3-expressing advanced solid tumors. J Clin Oncol. 2017;35 (suppl15):TPS2597-TPS2597. doi:10.1200/JCO.2017.35.15_suppl. TPS2597

11. Walunas TL, Lenschow DJ, Bakker CY, et al. CTLA-4 can function as a negative regulator of $\mathrm{T}$ cell activation. Immunity. 1994;1 (5):405-413. doi:10.1016/1074-7613(94)90071-X

12. Pardoll DM. The blockade of immune checkpoints in cancer immunotherapy. Nat Rev Cancer. 2012;12(4):252. doi:10.1038/nrc3239

13. Lynch TJ, Bondarenko I, Luft A, et al. Ipilimumab in combination with paclitaxel and carboplatin as first-line treatment in stage IIIB/IV non-small-cell lung cancer: results from a randomized, double-blind, multicenter phase II study. J Clin Oncol. 2012;30(17):2046-2054. doi:10.1200/JCO.2011.38.4032

14. Hu P, Liu Q, Deng G, et al. The prognostic value of cytotoxic T-lymphocyte antigen 4 in cancers: a systematic review and meta-analysis. Sci Rep. 2017;7:42913. doi:10.1038/srep42913

15. Chang K, Pastan I, Willingham MC. Isolation and characterization of a monoclonal antibody, K1, reactive with ovarian cancers and normal mesothelium. Int J Cancer. 1992;50(3):373-381. doi:10.1002/(ISSN) 1097-0215

16. Kelly RJ, Sharon E, Pastan I, Hassan R. Mesothelin-targeted agents in clinical trials and in preclinical development. Mol CancerTer. 2012;11(3):517-525. doi:10.1158/1535-7163.MCT-11-0454

17. Miettinen M, Sarlomo-Rikala M. Expression of calretinin, thrombomodulin, keratin 5, and mesothelin in lung carcinomas of different types: an immunohistochemical analysis of 596 tumors in comparison with epithelioid mesotheliomas of the pleura. Am J Surg Pathol. 2003;27(2):150-158. doi:10.1097/00000478-200302000-00002

18. Frierson HF Jr, Moskaluk CA, Powell SM, et al. Large-scale molecular and tissue microarray analysis of mesothelin expression in common human carcinomas. Hum Pathol. 2003;34(6):605-609. doi:10.1016/S0046-8177(03)00177-1

19. Ordóñez NG. The immunohistochemical diagnosis of mesothelioma: a comparative study of epithelioid mesothelioma and lung adenocarcinoma. Am J Surg Pathol. 2003;27(8):1031-1051. doi:10.1097/00000478-200308000-00001

20. Ordóñez NG. The diagnostic utility of immunohistochemistry in distinguishing between epithelioid mesotheliomas and squamous carcinomas of the lung: a comparative study. Mod Pathol. 2006;19 (3):417. doi:10.1038/modpathol.3800544

21. Amin MB, Greene FL, Edge SB, et al. The Eighth Edition AJCC Cancer Staging Manual: continuing to build a bridge from a population-based to a more "personalized" approach to cancer staging. CA Cancer J Clin. 2017;67(2):93-99. doi:10.3322/caac.21388
22. Byers LA, Rudin CM. Small cell lung cancer: where do we go from here? Cancer. 2015;121(5):664-672. doi:10.1002/cncr.29098

23. PS N, Kaur R, Kajal NC, Rana S. A non smoker presenting as small cell carcinoma: a Rare case report. Int $J$ Curr Res Med. 2017;3:62-65.

24. Varghese AM, Zakowski MF, Yu HA, et al. Small cell lung cancers in patients who never smoked cigarettes. J Thorac Oncol. 2014;9 (6):892-896. doi:10.1097/JTO.0000000000000142

25. e Castro T, Clemente J, Carvalho L, et al. Small-cell lung cancer in never-smokers: a case series. Lung Cancer. 2016;93:82-87. doi:10.1016/j.lungcan.2016.01.006

26. Rekhtman N. Neuroendocrine tumors of the lung: an update. Arch Pathol Lab Med. 2010;134(11):1628-1638. doi:10.1043/2009-0583RAR.1

27. Carbone DP, Morgensztern D, Le Moulec S, et al. Efficacy and safety of rovalpituzumab tesirine in patients with DLL3expressing, $\geq 3$ rdline small cell lung cancer: results from the phase 2 TRINITY study. J Clin Oncol. 2018;36(15_suppl):8507. doi:10.1200/JCO.2018.36.15_suppl.8507

28. Tanaka K, Isse K, Fujihira T, et al. Prevalence of Delta-like protein 3 expression in patients with small cell lung cancer. Lung Cancer. 2018;115:116-120. doi:10.1016/j.lungcan.2017.11.018

29. Saito M, Saito K, Shiraishi K, et al. Identification of candidate responders for anti-PD-L1/PD-1 immunotherapy, Rova-T therapy, or EZH2 inhibitory therapy in small-cell lung cancer. Mol Clin Oncol. 2018;8(2):310-314. doi:10.3892/mco.2017.1536

30. Liu Y, Yan L, He J, et al. The correlation of DLL3 expression with high-grade pulmonary neuroendocrine carcinoma clinicopathologic features and prognose. J Thorac Oncol. 2017;12(Suppl 2):S1736. doi:10.1016/j.jtho.2017.09.304

31. https://news.abbvie.com/news/phase-3-trial-rova-t-as-second-line-the rapy-for-advanced-small-cell-lung-cancer-tahoe-study-halted.htm. Acces sed 11 March, 2019

32. https://www.clinicaltrials.gov/. Accessed 12 October. 2018

33. Saunders LR, Bankovich AJ, Anderson WC, et al. A DLL3-targeted antibody-drug conjugate eradicates high-grade pulmonary neuroendocrine tumor-initiating cells in vivo. Sci Transl Med. 2015;7 (302):302ra136-302ra136. doi:10.1126/scitranslmed.aac9459

34. Koshkin VS, Reynolds J, Elson P, et al. Molecular profiling of small cell bladder cancer (SCBC) to reveal gene expression determinants of an aggressive phenotype. J Clin Oncol. 2017;35:Abstrnr 4529. doi:10.1200/JCO.2017.35.15_suppl.4529

35. Zhang Y, Liu W, Mojica W. Delta-like 3 expression in gastrointestinal neuroendocrine tumors portends new therapeutic options. Gastroenterology. 2017;152(5):S669. doi:10.1016/S0016-5085(17) 32356-9

36. Paulsen -E-E, Kilvaer TK, Rakaee M, et al. CTLA-4 expression in the non-small cell lung cancer patient tumor microenvironment: diverging prognostic impact in primary tumors and lymph node metastases. Cancer Immunol Immunother. 2017;66(11):1449-1461. doi:10.1007/s00262-017-2039-2

37. Contardi E, Palmisano GL, Tazzari PL, et al. CTLA-4 is constitutively expressed on tumor cells and can trigger apoptosis upon ligand interaction. Int J Cancer. 2005;117(4):538-550. doi:10.1002/(ISSN) 1097-0215

38. Salvi S, Fontana V, Boccardo S, et al. Evaluation of CTLA-4 expression and relevance as a novel prognostic factor in patients with non-small cell lung cancer. Cancer Immunol Immunother. 2012;61 (9):1463-1472. doi:10.1007/s00262-012-1211-y

39. Roncella S, Laurent S, Fontana V, et al. CTLA-4 in mesothelioma patients: tissue expression, body fluid levels and possible relevance as a prognostic factor. Cancer Immunol Immunother. 2016;65 (8):909-917. doi:10.1007/s00262-016-1844-3

40. Mao H, Zhang L, Yang Y, et al. New insights of CTLA-4 into its biological function in breast cancer. Curr Cancer Drug Targets. 2010;10(7):728-736. doi:10.2174/156800910793605811 
41. Laurent S, Queirolo P, Boero S, et al. The engagement of CTLA-4 on primary melanoma cell lines induces antibody-dependent cellular cytotoxicity and TNF- $\alpha$ production. J Ttransl Med. 2013;11(1):108. doi:10.1186/1479-5876-11-108

42. Huang P, Guo S, Zhang Y, Lu J, Chen Q, Tang L. Tumor CTLA-4 overexpression predicts poor survival in patients with nasopharyngeal carcinoma. Oncotarget. 2016;7(11):13060-13068.

43. Brahmer JR, Tykodi SS, Chow LQ, et al. Safety and activity of antiPD-L1 antibody in patients with advanced cancer. $N$ Engl J Med. 2012;366(26):2455-2465. doi:10.1056/NEJMoa1200694

44. Ready N, Farago AF, de Braud F, et al. Third-line nivolumab monotherapy in recurrent SCLC: checkMate 032. J Thorac Oncol. 2019;14 (2):237-244. doi:10.1016/j.jtho.2018.10.003

45. Ordóñez NG. Application of mesothelin immunostaining in tumor diagnosis. Am J Surg Pathol. 2003;27(11):1418-1428. doi:10.1097/ 00000478-200311000-00003

46. Thomas A, Chen Y, Steinberg SM, et al. High mesothelin expression in advanced lung adenocarcinoma is associated with KRAS mutations and a poor prognosis. Oncotarget. 2015;6(13):11694. doi:10.18632/oncotarget.v6i13

47. Kachala S, Bograd AJ, Villena-Vargas J, et al. Mesothelin overexpression is a marker of tumor aggressiveness and is associated with reduced recurrence-free and overall survival in early-stage lung adenocarcinoma. Clin Cancer Res. 2014;20(4):1020-1028. doi:10.1158/1078-0432.CCR-13-1862

48. Yen MJ, Hsu C-Y, Mao T-L, et al. Diffuse mesothelin expression correlates with prolonged patient survival in ovarian serous carcinoma. Clin Cancer Res. 2006;12(3):827-831. doi:10.1158/ 1078-0432.CCR-05-1397

49. Baba K, Ishigami S, Arigami T, et al. Mesothelin expression correlates with prolonged patient survival in gastric cancer. J Surg Oncol. 2012;105(2):195-199. doi:10.1002/jso.22024

50. Illei PB, Alewine C, Zahurak M, et al. Mesothelin expression in advanced gastro-esophageal cancer represents a novel target for immunotherapy. Appl Immunohistochem Mol Morphol. 2016;24 (4):246. doi:10.1097/PAI.0000000000000292

51. Ito T, Kajino K, Abe M, et al. ERC/mesothelin is expressed in human gastric cancer tissues and cell lines. Oncol Rep. 2014;31(1):27-33. doi:10.3892/or.2013.2803

52. Einama T, Kamachi H, Nishihara H, et al. Co-expression of mesothelin and CA125 correlates with unfavorable patient outcome in pancreatic ductal adenocarcinoma. Pancreas. 2011;40(8):1276-1282. doi:10.1097/MPA.0b013e318221bed8

53. Kawamata F, Kamachi H, Einama T, et al. Intracellular localization of mesothelin predicts patient prognosis of extrahepatic bile duct cancer. Int J Oncol. 2012;41(6):2109-2118. doi:10.3892/ijo.2012.1662
54. Parinyanitikul N, Blumenschein GR, Wu Y, et al. Mesothelin expression and survival outcomes in triple receptor negative breast cancer. Clin Breast Cancer. 2013;13(5):378-384. doi:10.1016/j. clbc.2013.05.001

55. Shimizu A, Hirono S, Tani M, et al. Coexpression of MUC 16 and mesothelin is related to the invasion process in pancreatic ductal adenocarcinoma. Cancer Sci. 2012;103(4):739-746. doi:10.1111/ cas.2012.103.issue-4

56. Winter JM, Tang LH, Klimstra DS, et al. A novel survival-based tissue microarray of pancreatic cancer validates MUC1 and mesothelin as biomarkers. PLoS ONE. 2012;7(7):e40157. doi:10.1371/journal.pone.0040157

57. Lamberts LE, Menke-van der Houven CW, ter Weele EJ, et al. ImmunoPET with anti-mesothelin antibody in patients with pancreatic and ovarian cancer before anti-mesothelin antibody-drug conjugate treatment. Clin Cancer Res. 2016;22(7):1642-1652. doi:10.1158/1078-0432.CCR-15-1272

58. Ali A, Brown V, Denley S, et al. Expression of KOC, S100P, mesothelin and MUC1 in pancreatico-biliary adenocarcinomas: development and utility of a potential diagnostic immunohistochemistry panel. BMC Clin Pathol. 2014;14(1):35. doi:10.1186/14726890-14-35

59. Tchou J, Wang L-C, Selven B, et al. Mesothelin, a novel immunotherapy target for triple negative breast cancer. Breast Cancer Res Treat. 2012;133(2):799-804. doi:10.1007/s10549-012-2018-4

60. Tozbikian G, Brogi E, Kadota K, et al. Mesothelin expression in triple negative breast carcinomas correlates significantly with basal-like phenotype, distant metastases and decreased survival. PLoS ONE. 2014;9(12):e114900. doi:10.1371/journal.pone.0114900

61. Weekes CD, Lamberts LE, Borad MJ, et al. Phase I study of DMOT4039A, an antibody-drug conjugate targeting mesothelin, in patients with unresectable pancreatic or platinum-resistant ovarian cancer. Mol Cancer Ther. 2016;15(3):439-447. doi:10.1158/15357163.MCT-15-0693

62. Zhao H, Davydova L, Mandich D, Cartun RW, Ligato S. S-100A4 protein and mesothelin expression in dysplasia and carcinoma of the extrahepatic bile duct. Am J Clin Pathol. 2007;127(3):374-379. doi:10.1309/37RTWYAEPABYY410

63. Ordóñez NG, Sahin AA. Diagnostic utility of immunohistochemistry in distinguishing between epithelioid pleural mesotheliomas and breast carcinomas: a comparative study. Hum Pathol. 2014;45 (7):1529-1540. doi:10.1016/j.humpath.2014.03.006

64. Bauerschlag D, Bräutigam K, Moll R, et al. Systematic analysis and validation of differential gene expression in ovarian serous adenocarcinomas and normal ovary. J Cancer Res Clin Oncol. 2013;139 (2):347-355. doi:10.1007/s00432-012-1334-8
OncoTargets and Therapy

\section{Publish your work in this journal}

OncoTargets and Therapy is an international, peer-reviewed, open access journal focusing on the pathological basis of all cancers, potential targets for therapy and treatment protocols employed to improve the management of cancer patients. The journal also focuses on the impact of management programs and new therapeutic agents and protocols on patient perspectives such as quality of life, adherence and satisfaction. The manuscript management system is completely online and includes a very quick and fair peer-review system, which is all easy to use. Visit http://www.dovepress.com/ testimonials.php to read real quotes from published authors. 